\title{
Experimentation Rather than Turnaround
}

Redesigning a business model is not done overnight, and it is wise not to risk everything on one endeavor. To succeed with business model innovations, companies need to conduct controlled experiments on their business models, in order to uncover what works and why. In that way, they can increase the likelihood that the business model will be successful when it is finally implemented in the entire market.

\section{II}

Fig. 6.1 Experimentation Rather than Turnaround

(C) The Author(s) 2018

S. Jørgensen, L. J. T. Pedersen, RESTART Sustainable Business Model Innovation, Palgrave Studies in Sustainable Business In Association with Future Earth, https://doi.org/10.1007/978-3-319-91971-3_6 


\subsection{The Science of Profitability}

Imagine if floodlights powered by kinetic energy illuminated the football pitches in poor districts around the world. It would imply that every time kids ran, jumped, did step-overs and tackles—in short, with every step they took on the pitch, electricity would be generated for lighting the pitch. Would not that be great?

If your answer to this question is affirmative, you can take pleasure in this already becoming a reality. There are currently two such pitches. One is located in the heart of Morro da Mineira, a favela in Rio de Janeiro, and the other in Lagos, Nigeria. The energy company Shell and the technology company Pavegen collaborate on the project. Pavegen's kinetic tiles, which generate electricity when someone steps on them, are located under the Astroturf. Previously, these pitches were largely unusable after dark - the kids had to play in the streets, and it was unsafe for them to be out after dark. This project quite literally sheds light, both in that it provides electricity to the lights on the pitch by means of green energy and in the sense that it illuminates the streets surrounding the pitch as a beneficial side effect. In this way, these companies experimented with a concrete solution for alternative energy production (Fig. 6.1).

Shell is unlikely to make a complete turnaround toward renewable energy any time soon, and football players running around on kinetic tiles will probably not solve our future energy needs. Many similar solutions are emerging simultaneously, however, such as the new solar tile-covered sidewalks along parts of Route 66 in the US, where the surface of the road itself generates electricity. Shell and other energy companies are looking for new and renewable energy sources that can meet the increasing energy demand. Therefore, the big players experiment with such innovative solutions, also in cooperation with small companies like Pavegen. Eventually, they will perhaps find solutions that can be scaled up and constitute sustainable innovations in the energy market. 


\section{Do Not Put All the Eggs in the Same Basket}

Across industries and countries, companies carry out business model innovations to become more sustainable. This comprises innovation in products, services, processes and entire business models. Design and innovation of business models is challenging, and it is perhaps best described as business model experimentation (Chesbrough 2010; Foss and Saebi 2017). We often compare business model innovation to changing the wheels on the car while driving. If you do an online image search, you can in fact find pictures of people who mastered the art of changing the wheels on moving cars, but it is at least wise to change one wheel at a time. The same is true for business model innovation-complete and sudden turnarounds can go wrong and thus be very destructive.

Netflix is often seen as a role model for companies that want to innovate their business model, but Netflix also learned from experience the hard way why experimentation rather than turnaround is the way to go for succeeding with business model innovation. In 2011, Netflix had parallel offerings_-its parallel streaming service, as we know it today, and DVD rentals online. The subscription fee for the combined service was 10 USD, and Netflix had decided to increase it to 16 USD but also to give customers the opportunity to choose only one of the two services for 8 USD. When Netflix announced its price changes, it immediately met a storm of complaints from its customers-the company even had to hire new service workers to handle all the requests. Not only that, Netflix's stock price fell by 51 percent in a short time.

However, the bad news was far from over. In an attempt to deal with the self-inflicted crisis, the company made another big move: Netflix announced that it would split the company into two entities; the streaming service would continue as Netflix, while a spin-off company called Qwikster would manage DVD rentals. Customers became even angrier and responded swiftly, which in turn meant that Netflix dropped the plans to split the company. 
As pointed out by the leading experimental economists John List and Uri Gneezy, Netflix's pricing blunder was fundamentally a consequence of putting all its eggs in the same basket when it carried out not one but two turnarounds (List and Gneezy 2014). As it turned out, the changes were based on incorrect hypotheses about what customers wanted, and the whole story essentially reads as a study in self-harm. The important question, of course, is why did not Netflix experiment with its pricing model in a controlled manner? It could have tested the new model in only parts of the market — for instance, Texas or Florida — and study the effects of the change while continuing with the old model in the rest of the market. If analyses showed that the change was successful, Netflix could have implemented the model in the rest of the market.

Netflix survived its pricing problems in 2011, and in the US market, its DVD rental service and its streaming service still coexist. Since the stock price drop of 2011, the Netflix stock has risen and risen. However, in the period in question, the company incurred large, unnecessary losses. Who knows how the stock price and the company's reputation in the US market would have fared if it had experimented with its pricing model in a controlled fashion, rather than conduct turnarounds that did not work?

IBM is often viewed as a pioneer in business model experimentation, and the innovation scholar Clayton Christensen has argued that the company is a role model with regard to allowing for experimentation. IBM has made major changes in its value propositions many times: from its huge mainframe computers to the more compact computers it later produced, and then from laptops to information systems and other databased services. Every time the company has carried out such an innovation process, it placed the new business unit in a new location: Poughkeepsie, New York; Rochester, Minnesota; Boca Raton, Florida, and finally, New York City. In this way, the company created space and freedom for experimentation in the new business units. Out of range of the protectors of the establishment, while still being sheltered by the safe revenue streams from the existing business areas, the developers of new solutions could experiment undisturbed and develop IBM's new products and services. In this way, the company has succeeded in rewriting its history many times, but in controlled ways that enable radical innovations. And who knows where the company will go next, and what it is going to offer from there? 


\section{Control, Experiment and Innovate!}

To succeed with business model innovation, companies must therefore think like scientists. Experimentation under controlled conditions can provide insight into what works and what does not, and it can reduce the risk of innovation (cf. McGrath 2010; Thomke 2001). In innovation circles, it has become a mantra that entrepreneurs should "fail fast". The logic goes that this allows them to learn from quick failure, instead of working for a long time on wrongful assumptions, and then fail when finally launching the product or service (Ries 2011). However, we should add an important element: If you fail quickly, be sure to fail in a controlled manner. Failure can be an important part of the innovation process, but one should preferably not fail in the manner and on the scale that Netflix did in the pricing story from 2011. Trial and error, however, is a good strategy for business model experimentation, as long as it is done in a controlled way (Davenport 2009).

There are several different ways to experiment with business models (see, e.g., Anderson 2011; Andries et al. 2013; Simester 2017). Firstly, there are the major experiments of the IBM variety, wherein a company is looking for new or alternative ways to create value. In such cases, the company typically explores the possibility of new business models in parallel with the existing business model (see, e.g., Andries et al. 2013). The oil and energy company Equinor's new business area New Energy Solutions and BMW's car sharing service Drivenow in Germany and the UK are examples of large companies exploring alternative business models within the boundaries of business-as-usual. For companies that expect significant changes in customers' consumption patterns in the future, or other changes that would threaten their existing business models, this is a sensible way to approach the transition toward new ways of creating, delivering and capturing value.

Secondly, business model experimentation deals with the many small and large changes in the ways a company creates, delivers and captures value (Morris et al. 2005). At first glance, the change in the pricing model of Netflix is not a major change, but the consequences for the company were dramatic. Business models are never complete-they are typically redesigned continuously and reiteratively, as big and small changes are 
made in what is offered to the customer, which inputs are used, how products and services are delivered to the customer, how to reduce costs, and so on. An important type of business model experimentation thus relates to conducting controlled trials that make it possible to assess the impact of planned changes.

\section{Changes Big and Small}

Experimentation can lead to both major shifts and minor changes in business models. When we talk about innovation, it is easy to think of the large and comprehensive changes. In recent years, there has been a lot of talk about so-called disruptive innovations, and it is almost as if all companies are supposed to be radically innovative. Given how the earth's population is pushing the boundaries of both society and the environment, it is to be expected that academics and others call for fundamental changes and technologies that can turn business upside-down. Many people argue that we are in need of a new "moon landing" — an ambitious goal toward which business and society can strive. In particular, the call for such ambitious action is widespread in relation to the climate problem.

Such breakthrough innovations are important, and there is reason to expect that in the near future companies will revolutionize the way we travel, that they will find new sources of energy, that they will find more sustainable alternatives to our current meat-based diet and that companies can even help solve the poverty problem (see, e.g., Elkington and Zeitz 2014). However, it is important that ordinary companies do not lose heart just because they are not in the business of conducting such radical innovations. Most innovations are actually incremental, and not all sustainable business models need to be radical deviations from existing business models.

Although radical innovations get the most attention, it is often improvements and diffusion of already implemented innovations that have the greatest effect (Christensen 2013). The first electric cars were such a radical innovation, but the subsequent incremental improvements in battery capacity and production method have been crucial for unlock- 
ing the impact of this technology on society and the environment. Of course, radical changes that are implemented on a large scale can also have major impact. Interesting examples in our time include 3D printing, which can reduce the need for transport and associated emissions, and large companies replacing fossil fuels with renewable energy on a grand scale. Both incremental and radical innovations can create considerable value to society and the environment.

If we want to stop sawing off the branch we are sitting on, it will require that many companies change their business models in ways that have a large combined effect. Some companies can make small adjustments that have high scalability, while others need to make major changes to their business models for comparable effect on their footprints. What constitutes big and small effects depends on what you measure. If you want to influence the lives of people at the bottom of the pyramid, or ensure better integration of immigrants, the number of people who receive aid and the extent to which they get help is the measure of success. If the objective is to reduce $\mathrm{CO}_{2}$ emissions, the use of harmful substances or other externalities is what needs to be measured.

People running around on Pavegen's kinetic tiles may not light the large cities of the future. As such, the project's biggest value for Pavegen and Shell is perhaps that it serves as an example of experimentation with the energy industry's business model. However, the technology that Pavegen and Shell are now testing in the Brazilian favela must be seen in conjunction with other rival and complementary technologies that contribute to changes in how energy is generated, stored and distributed. While the Brazilian kids generate electricity by running around on the football pitch, a multitude of companies simultaneously implement a variety of technologies for energy production, thus contributing to the same shift. Scatec Solar builds solar parks in Africa; Bright Products develops solar panels and house systems for poor parts of the world; Otovo Solar puts solar panels on the rooftops of customers; Langlee Wave Power builds systems for exploiting wave power and Statkraft installs more and more wind turbines. The sum of all of these changes can prove significant for the green transition in energy production and consumption. 
In order to succeed in a transition to sustainable business, we need both big radical shifts and many small movements in the right direction. And as in the example of the football pitch, we need various players in the market to experiment together to create this movement-thus creating an ecosystem for innovation. Sustainable business requires innovation on a large scale, but a necessary step is to test ideas in new and existing markets (Bocken et al. 2017). This underscores the need for controlled experimentation.

\subsection{Asking the Right Questions}

I don't understand why investors would want this information. Why should they care about the environment when they invest their savings?

An Italian finance professor had asked the question, after being told about the large field experiment Lars Jacob and his colleague Trond Døskeland had carried out during the launch of the Norwegian bank Skandiabanken's implementation of an ethical labeling system for mutual funds. Skandiabanken (since renamed Sbanken) had developed the system in an attempt to provide the individual investors for whom the system was designed with actionable non-financial information about their investment opportunities. As part of the implementation, the two researchers conducted a large-scale experiment in collaboration with the bank, in order to examine how the labeling system influenced the investment behavior of individual investors.

The labeling system was launched in 2011 and involved a classification of the bank's mutual funds into four categories: "Red funds" are funds containing investments a significant proportion of customers are expected to find problematic. Examples include weapon-producing companies and companies operating in highly corrupt markets. "Neutral funds" are funds that neither contain investments that are considered ethically problematic nor stand out positively in terms of ethicality. "Green funds" were categorized into two levels and contained funds that actively avoid investing in ethically problematic enterprises and funds that actively seek 
to invest in responsible companies, respectively. When Skandiabanken's customers look at the overview of available mutual funds distributed by the bank, all funds are marked with symbols reflecting one of the four categories. Thus, it is easy for customers to differentiate between mutual funds of different ethicality.

In this way, Skandiabanken made it possible for customers to assess mutual funds also with regard to ethicality. This was a new service to customers - or at least an extension of its existing services. However, little was known about the degree to which customers were interested in this kind of information, and what would be the most effective way to make the information usable for them in their purchasing decisions. To acquire knowledge about this, Lars Jacob and Trond designed a large field experiment together with the management of the bank. In their experiment, they studied the behavior of 140,000 individual investors. They constructed three comparable customer groups and controlled what information each group received about the system. One group received financially framed information, one group received information that emphasized the ethical characteristics of the funds and one control group received no information about the labeling system. This made it possible to investigate which information made it more likely that investors used the information from the ethical labeling system in their investment decisions (see Døskeland and Pedersen 2015, 2017). Based on this insight, Skandiabanken could adapt the communication about the system to all of its customers.

Skandiabanken could have implemented the new system to all of its customers at once. However, by using one month in which they tested different versions on different customer groups, it acquired valuable knowledge about how investors reacted to and used the system. This knowledge could in turn be used in the implementation of the ethical labeling system - a system that has led to changes in customers' investment behavior, and thus shifted their investments in a greener direction (Døskeland and Pedersen 2016). 


\section{Experimentation in Practice}

Business model experimentation can take many forms, ranging from the design and testing of new product and service prototypes to experimentation with new business models in new markets (Chesbrough 2007). This implies that experimentation may be linked to each of the three components of the business model that we have previously introduced. As illustrated below, a series of questions can be asked as a point of departure for developing experiments relating to each of them.

Regarding value propositions, there are at least three basic questions that must be answered and that can provide ground for experimentation. Who will our customer be, and what kind of market segments will we aim for? What is our hypothesis about what these customers want? And what does that mean for the design of products and/or services that we will offer in order to create value for these customers (Morris et al. 2005)? When Skandiabanken developed its ethical labeling system, it was still unclear whether this was something the average individual investor would benefit from or if a specific niche of ethically conscious investors were the real target group. The research that was carried out showed that the system did in fact change the investment behavior of its customers, which implies that the service may have been more useful than expected among the customers. However, how a service of this type is designed and communicated to customers is central to how it is used. Therefore, controlled trials of how the service works and is used are necessary.

We can explore value delivery using similar questions: Which resources are needed to deliver in line with the value proposition, and how can those resources alternatively be used to solve other problems? Which activities are key to successful value delivery, and what other kinds of problems can be solved by means of comparable activities? Which partners are central for enabling the value delivery the company must carry out, and what other possibilities are there to create value based on the same alliances (cf. Chesbrough 2010; Adner 2006)? There are several examples of companies that have experimented with developing new services based on existing resources. We have previously shown how StormGeo used existing knowledge and meteorological data to develop 
new services to other market segments. Amazon is another example of a company that has developed a range of innovative services based on its technological platform, which has enabled it to go from being a pure online store to provide a multitude of services within storage, cloud services, research and much more (see, e.g., Brandt 2011; Osterwalder and Pigneur 2010).

Finally, we can ask questions related to value capture, which can inform experimental thinking about revenue streams, payment models, cost structures and so on. How will customers pay? How much does it cost to deliver on the value proposition? And what are the company's ambitions with regard to growth and scope, with regard to what position it wants to take in the market (cf. Morris et al. 2005)? This is fertile ground for experimentation, not at least with regard to payment models. The past decade has seen the emergence of many new payment models, including various streaming services, sharing-economic business models and payas-you-go solutions (PAYG), in which the customer pays in installments during the use of the product (see, e.g., Guajardo 2016). There is large potential in finding payment models that are attractive to customers, and it can be the key to attract customers you otherwise would not have. This is particularly evident at the so-called bottom of the pyramid, that is, in markets (e.g., in parts of Africa and Asia) where the purchasing power is so low that large groups of customers cannot afford essential products and services (Prahalad 2012). In these markets, we have seen the emergence of payment models — not at least pay-as-you-go solutions-that have made it possible to penetrate vast markets with customers who would otherwise not have been able to afford products such as solar panels, stoves and so on.

None of these issues directly relates to sustainability as such, but they are nevertheless crucial for companies that aim to conduct sustainable business. Creating sustainable and profitable business models necessitates experimentation with different customers in different markets and with various ways of delivering and capturing value. In our experience, there is increasing willingness among companies to experiment with completely new business models and to make changes to existing ones. We see this across numerous industries, and in order to be successful, companies go 


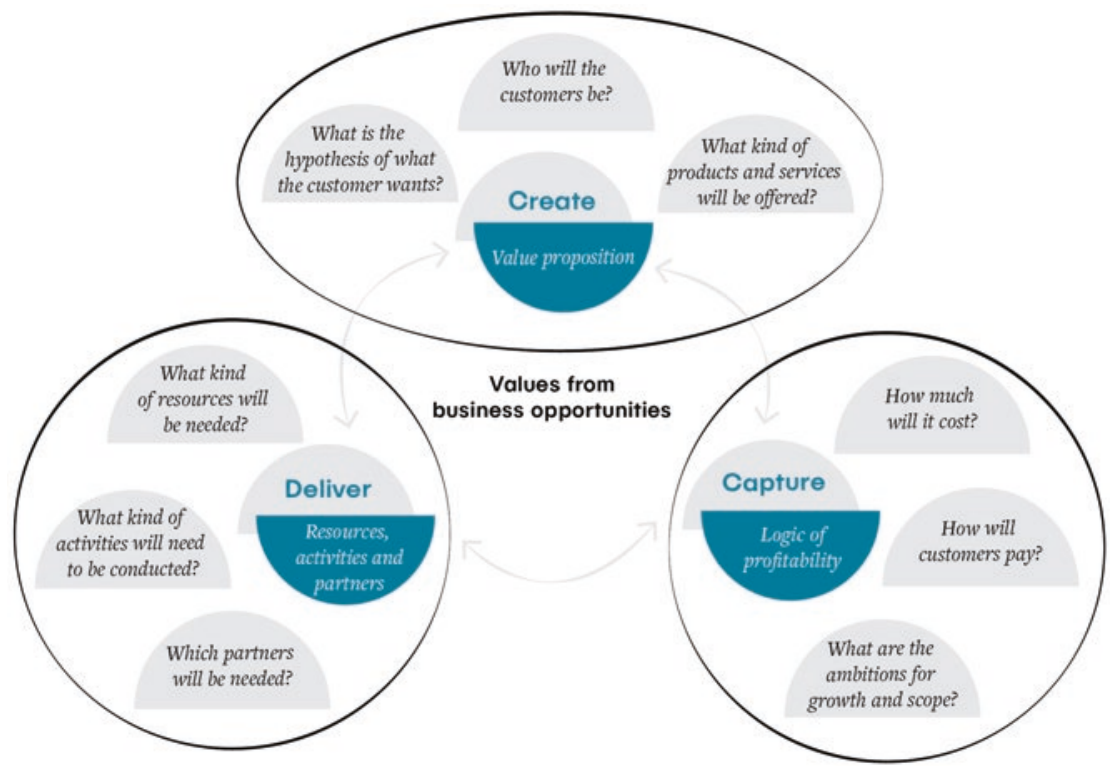

Fig. 6.2 Questions underlying business model experimentation in practice

back to the drawing board and start with questions of the kind we have outlined here (Fig. 6.2).

On the road to sustainable business, many of our current solutions, technologies and production and consumption patterns will likely disappear and be replaced by new ones. It remains to be seen what kind of products and services that will solve our problems, how they will be offered to us from companies and how they will make them, not to mention how we are going to pay for them. However, when all four wheels on the car may need to be replaced while it is still in motion, it means that companies will have to experiment their way forward, systematically. We see this when Levis experiments with the very first 100 percent recycled denim jeans. We see it when aquaculture giants such as Marine Harvest invest in fish farming in closed tanks or in facilities on land. And we see it when companies like Otovo Solar cover the cost of adding solar panels on people's houses, who in turn pay for access to the electricity that is generated, while they can offer excess energy production for sale to their neighbors. Thus, households may get lower costs related to the purchase 
of electricity. The movement toward sustainable business requires this type of controlled experimentation, so it becomes possible to move in the right direction step by step. In the next chapter, we will show how services can play an important role in this development.

\section{References}

Adner, R. (2006). Match your innovation strategy to your innovation ecosystem. Harvard Business Review, 84(4), 98.

Anderson, E. T. (2011). A step-by-step guide to smart business experiments. Development and Learning in Organizations: An International Journal, 25(6). Andries, P., Debackere, K., \& Looy, B. (2013). Simultaneous experimentation as a learning strategy: Business model development under uncertainty. Strategic Entrepreneurship Journal, 7(4), 288-310.

Bocken, N., Miller, K., Weissbrod, I., Holgado, M., \& Evans, S. (2017). Business Model Experimentation for Circularity: Driving sustainability in a large international clothing retailer. Economics and Policy of Energy and the Environment (EPEE).

Brandt, R. L. (2011). One click: Jeff Bezos and the rise of Amazon.com. London: Penguin.

Chesbrough, H. (2007). Business model innovation: It's not just about technology anymore. Strategy \& Leadership, 35(6), 12-17.

Chesbrough, H. (2010). Business model innovation: Opportunities and barriers. Long Range Planning, 43(2), 354-363.

Christensen, C. (2013). The innovator's dilemma: When new technologies cause great firms to fail. Cambridge, MA: Harvard Business Review Press.

Davenport, T. H. (2009). How to design smart business experiments. Harvard Business Review, 87(2), 68-76.

Døskeland, T., \& Pedersen, L. J. T. (2015). Investing with brain or heart? A field experiment on responsible investment. Management Science, 62(6), 1632-1644.

Døskeland, T., \& Pedersen, L. J. T. (2016). Does the wealth of investors matter? Evidence from a field experiment on responsible investment. Working paper. NHH Norwegian School of Economics.

Døskeland, T., \& Pedersen, L. J. T. (2017). Does the wealth of investors matter? Evidence from a field experiment on responsible investment. Working paper, NHH Norwegian School of Economics.

Elkington, J., \& Zeitz, J. (2014). The breakthrough challenge: 10 ways to connect today's profits with tomorrow's bottom line. London: John Wiley \& Sons. 
Foss, N. J., \& Saebi, T. (2017). Fifteen years of research on business model innovation: How far have we come, and where should we go? Journal of Management, 43(1), 200-227.

Guajardo, J. A. (2016). Pay-as-you-go business models in developing economies: Consumer behavior and repayment performance. Available at SSRN.

List, J., \& Gneezy, U. (2014). The why axis: Hidden motives and the undiscovered economics of everyday life. New York, NY: Random House.

McGrath, R. G. (2010). Business models: A discovery driven approach. Long Range Planning, 43(2), 247-261.

Morris, M., Schindehutte, M., \& Allen, J. (2005). The entrepreneur's business model: Toward a unified perspective. Journal of Business Research, 58(6), 726-735.

Osterwalder, A., \& Pigneur, Y. (2010). Business model generation: A handbook for visionaries, game changers, and challengers. London: John Wiley \& Sons.

Prahalad, C. K. (2012). Bottom of the pyramid as a source of breakthrough innovations. Journal of Product Innovation Management, 29(1), 6-12.

Ries, E. (2011). The lean startup: How today's entrepreneurs use continuous innovation to create radically successful businesses. New York, NY: Crown Books.

Simester, D. (2017). Field experiments in marketing. Handbook of Economic Field Experiments, 1, 465-497.

Thomke, S. (2001). Enlightened experimentation: The new imperative for innovation. Harvard Business Review, 79(2), 66-75.

Open Access This chapter is licensed under the terms of the Creative Commons Attribution-NonCommercial-NoDerivatives 4.0 International License (http:// creativecommons.org/licenses/by-nc-nd/4.0/), which permits any noncommercial use, sharing, distribution and reproduction in any medium or format, as long as you give appropriate credit to the original author(s) and the source, provide a link to the Creative Commons license and indicate if you modified the licensed material. You do not have permission under this license to share adapted material derived from this book or parts of it.

The images or other third party material in this chapter are included in the chapter's Creative Commons license, unless indicated otherwise in a credit line to the material. If material is not included in the chapter's Creative Commons license and your intended use is not permitted by statutory regulation or exceeds the permitted use, you will need to obtain permission directly from the copyright holder.

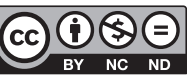

